\title{
Tusheti and its forests - a unique case of local governance in Georgia
}

\author{
Marika Kavtarishvili
}

Keywords: Georgia, local forest governance, protected landscape, Tusheti Mountains

\section{Abstract}

The Tusheti Protected Landscape (IUCN category V), together with the two other IUCN categories (Strict Nature Reserve - IUCN category I - and National Park IUCN Category II), is a part of the Tusheti Protected Areas. The Tusheti Protected Landscape covers 31518 ha, of which 10\% is forest. Tusheti Protected Landscape is unique within the protected areas of Georgia in that it is managed by the local selfgovernment, Akhmeta municipality. Tusheti Protected Areas were designated by the central government of Georgia in 2003.
Profile

Protected area

Tusheti Protected Areas

Mountain range

\section{Caucasus}

Country

\section{Georgia}

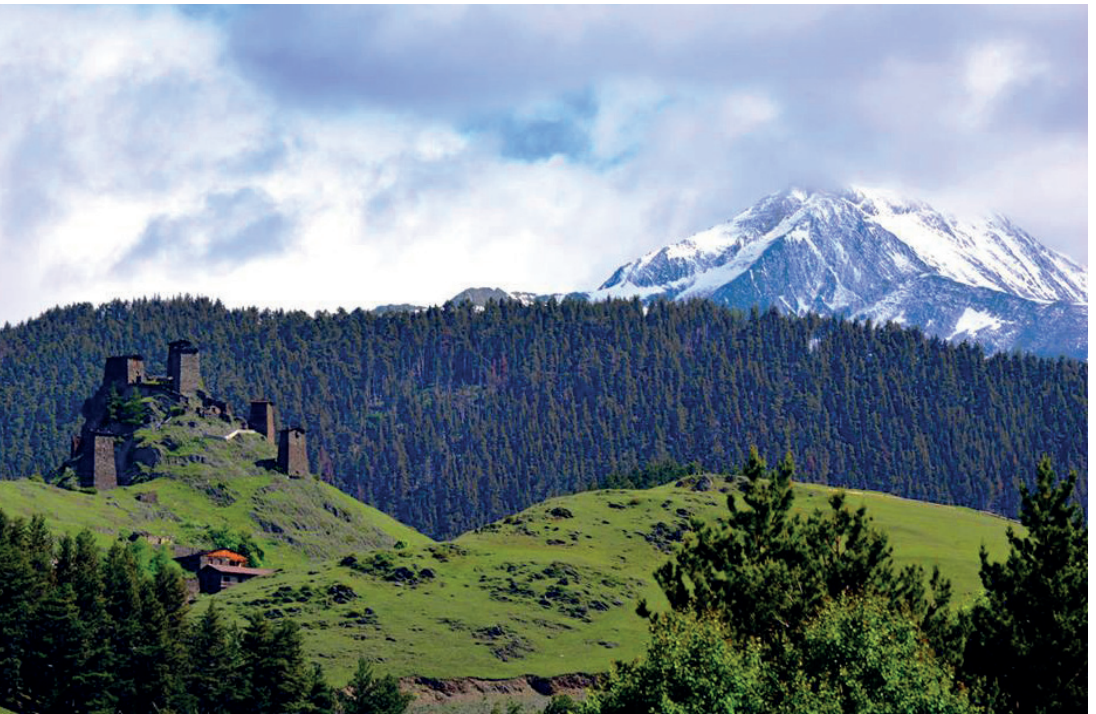

Figure 1 - Keselo Castle in Omalo Village. (C) S. Idoidze

\section{A jewel in the Caucasus}

The Caucasus is one of the biologically richest regions on Earth. It is one of WWF's 35 priority places and one of the 34 biodiversity hotspots identified by Conservation International (WWF CauPo 2012).

Georgia, which lies in the Caucasus, is diverse in landscapes and climates, with mountains dominant in the north, centre and south, but to the west and the east, lowland plains extend to the basins of the Black and Caspian seas. Two thirds of the country is mountainous. Georgia is rich in various types of ecosystems, habitats and associated species, including those that are used or are potentially important as food or other essential products (Resolution No-343. 08/05/2014).

Tusheti, one of the most beautiful regions of Georgia, is located within the eastern part of the Caucasus Mountains, bordering on Dagestan in the east and Chechnya in the north (both Russian Federation), and on the Georgian regions of Khevsureti in the west and Kakheti in the south-east. The unique nature and ethno-cultural realities make it extraordinary attractive and interesting (GCCW 2007). Tusheti is the most ancient highland region and has preserved rich traditions of the old oriental pastoral culture. Out of this pastoral culture and tradition Tushetian cultural and everyday peculiarities have developed, a system of values and the rule of life characteristic only to this place (Idoidze 2006).

\section{Natural-cultural landscape and climate of Tusheti}

Tusheti boasts a very rich landscape diversity. The mountainous landscape of the area was formed by various natural processes and human activities, and consists of mixed and coniferous forests, montane meadows, subalpine shrubs, subalpine and alpine grasslands and subnival areas. The pastoral culture and traditions have formed the typical landscape of Tusheti - a mosaic of small settlements, hay meadows, fields, pastures and forests (NCA CR \& KNPA 2013).

Tusheti is surrounded by high mountain ranges and peaks and is subdivided by numerous valleys. The water from these valleys flows together into two major rivers - the Pirikita Alazani and the Tushetis Alazani. These two rivers merge near the village of Shenako and then leave Tusheti and Georgia, passing through the territory of Dagestan and flowing into the Caspian Sea.

Tusheti consists of four main communities: the Pirikiti community of the villages in the upper part of Pirikita Alazani valley; the Gometsari community of the villages situated in the territories of the Gometsari Alazani valley; the Tsovata community in the Tsovata river basin, which is a part of the Gometsari river basin, while the Chaghma community has settled where 


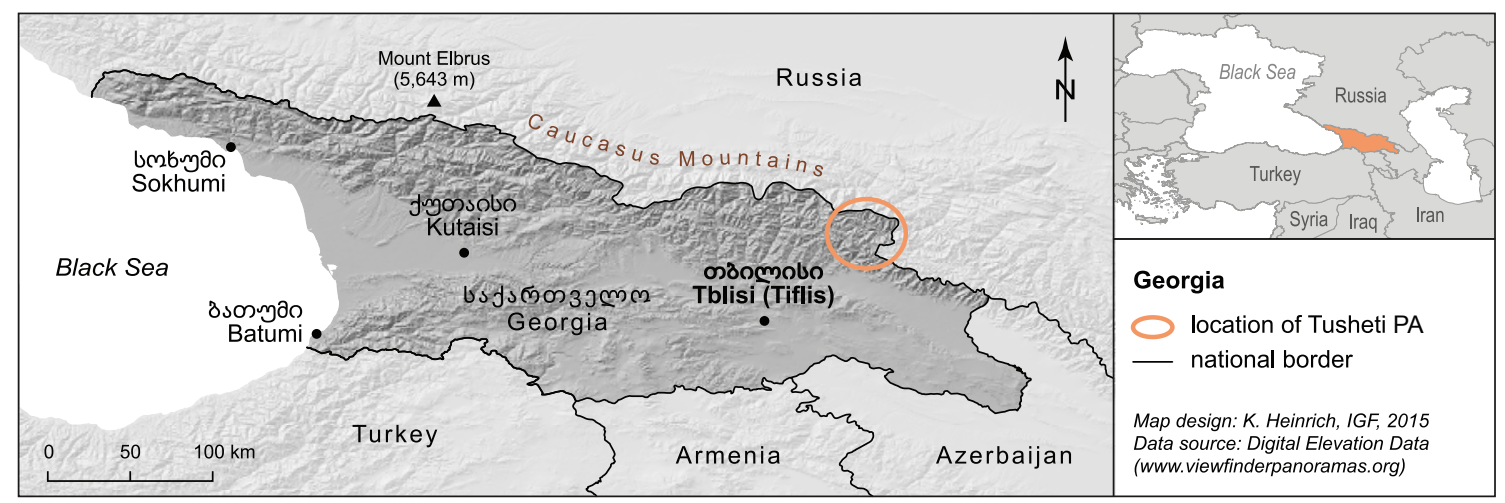

Figure 2 - Map of Georgia and location of the Tusheti Protected Areas

both Alazanis merge. Omalo, the administrative centre of Tusheti, belongs to the Chaghma community (GCCW 2007).

Tusheti has a temperate humid climate with relatively dry cold winters and short summers. A continental climate dominates in the eastern part of the region especially. However, local conditions (mainly precipitation) vary significantly from place to place, influenced by relief forms and altitude. Annual precipitation in the Sakorne pass (2970 m), for instance, is $1631 \mathrm{~mm}$, compared to $1064 \mathrm{~mm}$ in the Ortsklali gorge $(2260 \mathrm{~m})$, and it varies between $700-900 \mathrm{~mm}$ in other parts. The main range of the Great Caucasus and the Gometsari Alazani gorge are especially humid, some 10\% higher than in the Pirikita Alazani gorge. This difference is caused because the humidity is mostly brought in by southerly air masses (NCA CR \& KNPA 2013).

\section{Rich biodiversity and forests}

The Caucasus Region is one of the world's 34 Biodiversity Hotspots and Tusheti is part of it. Tusheti is one of the richest regions of Georgia in terms of plant and animal species diversity.

There are more than 1000 vascular plants of 92 families, i. e. one fourth of all species in Georgia. About $23 \%$ of all plant species are endemics (11 Georgian and 230 Caucasian). Four plant species are included in the Georgian Red List.

The region is also rich in fauna. There are $32 \mathrm{mam}-$ mals and about 90 bird species, including wild goat (Capra aegagrus) and East Caucasian tur (Capra cylindricornis), brown bear (Ursus arctos), Caucasian black grouse (Tetrao mlokosiewiczi) and the Caucasian snowcock (Tetraogallus caucasicus).

Tusheti is rich in agro-biodiversity, including cultural crops and animal breeds. Of the cultivated crop varieties barley is very significant. Tushetian horse, Tushetian sheep and Georgian shepherd dog are very important and well-known animal breeds.

The forest ecosystem is an essential part of the biodiversity of the whole Tusheti Protected Areas (PA).
The forests habitats in Tusheti are mainly composed of the pine (Pinus kochiana). Much smaller areas are covered by birch, and deciduous mixed forests have even more limited distribution. The vegetation belt is found at 1650-1800/1900 m. The subalpine forests range between $1800 / 1900$ and 2500/2600 m. Birch forests (composed by Betula pendula, B. litwinowii and B. raddeana) are found at $1700-2400 \mathrm{~m}$. Large areas of these forests are located on the northern slopes of the Vestomchevi valley.

In some places (e.g. around Omalo) pine forests are expanding because of changes in agricultural patterns. The largest areas of such forest stands are situated between the villages of Omalo and Bochorma on the south-western slopes of the Pirikita Range, between the villages of Shenaqo and Diklo, and between the villages of Khakhabo and Shtrolta. This trend will continue as a natural regeneration process on the secondary grasslands and meadows and will contribute to an increase of the total area of pine forests.

Alluvial alder forests are found in the small areas of natural floodplain habitats. They are present at the river banks together with Miricaria bracteata and willow shrubs (this type of habitat can be seen in the Pirikita Alazani River valley between Omalo and Shenako).

Subalpine shrubs are Rhododendron caucasicum communities at 2400-2800 m. Large areas of the shrubs are found along the Pirikita gorge, just above the subalpine forest and also on the northern slopes of the Tsovata valley (Resolution No-16, 03/01/2014, NCA CR \& KNPA 2013).

\section{Designation of Tusheti Protected Areas - a way to protect a unique ecosystem}

Tusheti, with its snowy peaks, unique pine forests and deep rivers, with its old villages and castles, has always been very attractive for visitors. This interest has various reasons: one of them is to see and experience local culture and traditions, but this place is also very attractive for ethnographers and biologists, photographers and adventurers. 


\section{Tus het i Prot e c t e d A r e a s}

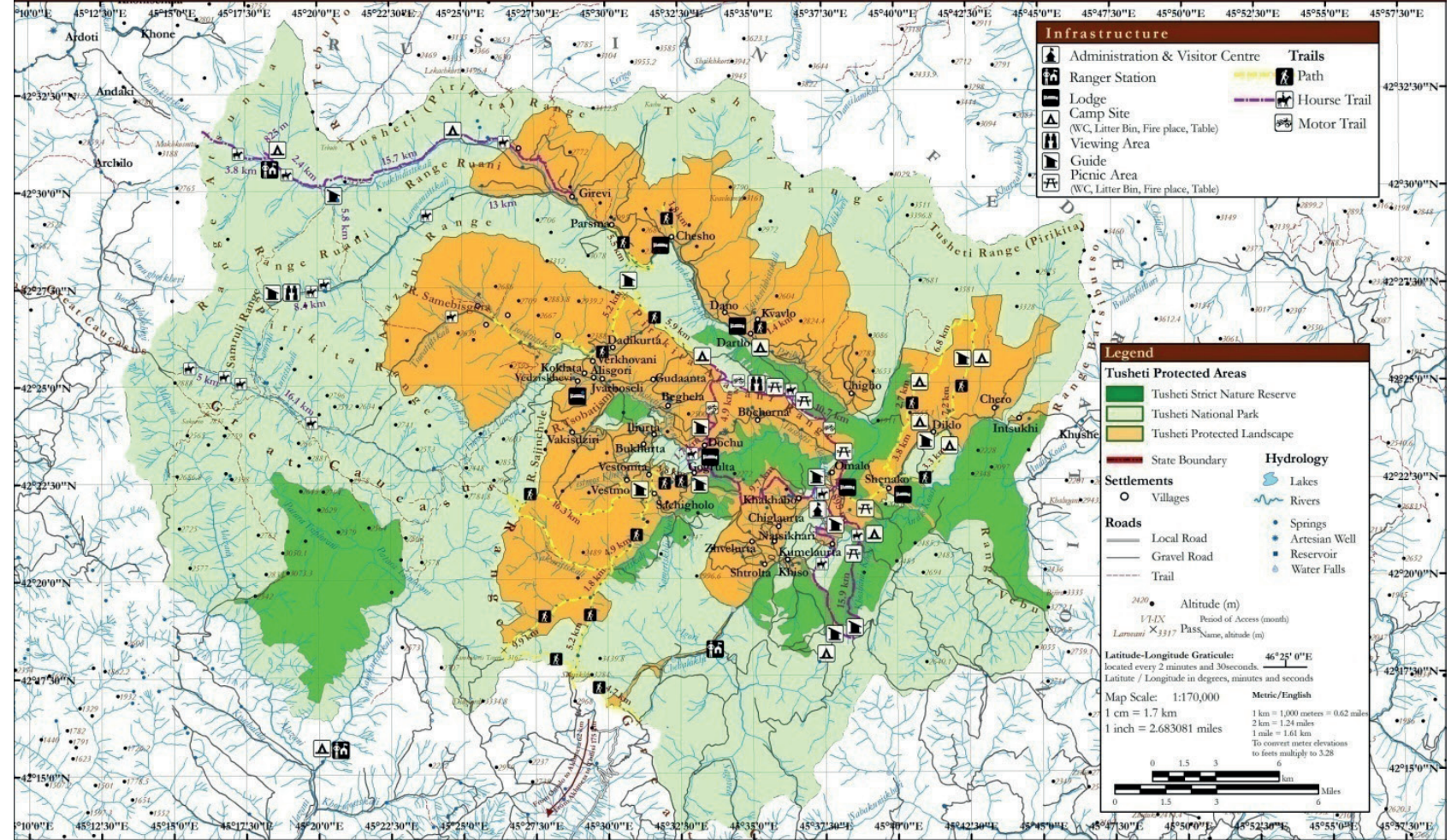

Figure 3 - Tusheti Protected Areas

In order to maintain the ecosystem in Tusheti and to protect its flora and fauna, the decision was taken in 1990 to establish Tusheti Reserve. Later on the area was integrated into Akhmeta Reserve, which also included Batsara and Babaneuri Reserves (GCCW 2007). In 2003 Tusheti PAs was established under the Georgian Law on the Establishment and Management of Tusheti, Batsara-Babaneuli, Lagodekhi and Vashlovani Protected Areas, and includes the following IUCN categories: Strict Nature Reserve (Category I, hereafter Tusheti SNR) covering $12627.2 \mathrm{ha}$, the National Park (Category II, hereafter Tusheti NP) covering $69515 \mathrm{ha}$, and the Protected Landscape (Category $\mathrm{V}$, hereafter Tusheti PL) covering 31518 ha (Resolution No-16, 03/01/2014).

The Tusheti PAs are situated in the Kakheti region, in the municipality of Akhmeta and represent the central part of the Caucasus Range, including a system of high mountains, varying from 1500 to $4500 \mathrm{~m}$ (GCCW 2007), see Figure 3.

Designation of the Tusheti PAs (including Tusheti PL) was the decision of the Georgian government. However, the process included active and intense consultations with the local population. The attitude of the local population towards the establishment of the protected areas was not positive from the beginning. Their key thought and concern was that they would be limited in their traditional lifestyle. They would be restricted in the use of their surrounding resources, etc. Moreover, they had concerns that in case of designation of the protected areas they would be forced to leave their historical places. It took quite some time and hard work to convince them of the benefits of the protected areas. This work included active educational and awareness-raising activities. The benefits from establishing the protected areas were later proven in practice. A number of investments and donor-funded projects came about in connection with the establishment of the protected areas, which served the development of the area as well as creating alternative sources of income for the local population. The locals started gaining economic benefits from tourism. Currently the local population has a very positive attitude towards the protected areas. Moreover, Tusheti PAs became the showcase for other places where the state government planned the establishment of protected areas. Presenting the results of the designation of Tusheti PAs, i.e. the development of the place and the direct benefits to the Tushetian population, easily convinced locals from Kazbegi, Javakheti and PshavKhevsureti. Designation of these three additional protected areas largely depends on the success of Tusheti PAs (Mr. A. Gogotidze 2015 pers. comm.).

\section{Tusheti Protected Landscape and manage- ment of its forest - an exceptional case in Georgia}

\section{Tusheti Protected Landscape}

Tusheti PL, classified as IUCN Category V, is located in the north-eastern part of Georgia ( $42^{\circ} 16^{\prime} 40^{\prime \prime}-$ $42^{\circ} 32^{\prime} 10^{\prime \prime} \mathrm{N}, 45^{\circ} 22^{\prime} 20^{\prime \prime}-45^{\circ} 45^{\prime} 15^{\prime \prime} \mathrm{E}$ ). It is situated 


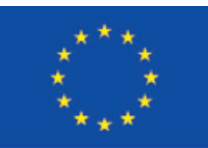

\section{ENPI FLEG II Program support for Tusheti PL forest management}

The IUCN Caucasus Cooperation Centre (IUCN CCC), which works in the three southern countries of the Caucasus, defined forests as one of its key priority areas (IUCN CCC, 2011ㄹ). IUCN CCC is implementing the regional EU-funded ENPI FLEG II Program², which promotes sustainable forest governance, management and protection of forests in Armenia, Azerbaijan, Belarus, Georgia, Moldova, Russia and Ukraine (About FLEG II Program, accessed 7 May 2015).

One of the key directions of the programme is to provide support in managing Locally Controlled Forests in Georgia. The ENPI FLEG II team in Georgia studied Forest Management in Tusheti PL and, based on the results, prepared a report on Opportunities and Challenges for Communal Forestry in Georgia. Both documents are available in English at: http://enpi-fleg.ge/geoforestportal/index.php/publications-iucn

To read more on the ENPI FLEG II Program, visit the official website at: www.enpi-fleg.org

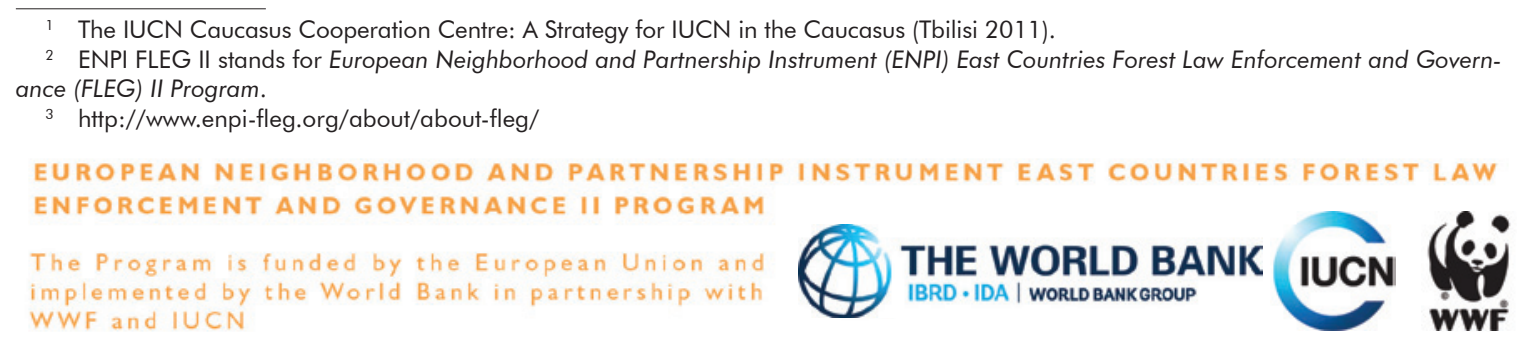

in the Kakheti region, in the municipality of Akhmeta and covers 31518 ha. Together with Tusheti SNR and Tusheti NP it forms the Tusheti PAs.

The goal of Tusheti PL is to protect nature as well as to preserve the cultural landscape, which is of high national importance and aesthetic value, established through the harmonic relationship between human and natural environments. In addition, Tusheti PL aims to preserve habitat areas and to develop the recreational use of its resources (Georgian Law No 2086Is, 22/04/2003).

Total forest coverage in Tusheti PL is about 3700 ha (Mr. A. Gogotidze and O. Ichirauli 2013 pers. comm.), equivalent to about $10 \%$ of the total area of the PL. The forests are situated mainly on steep slopes, which makes them an important protection against erosion and vital for improving water retention (NCA CR \& KNPA 2013).

The legal basis for managing Tusheti PL and its forests

Tusheti PL is an exception from other protected areas of Georgia - it is managed by the local self-governmental body of Akhmeta municipality.

The Georgian Code on Local Self-Government approved by the Georgian parliament defines self-governance as "the right and the ability of the locally registered population to take decisions on issues of local importance, in accordance with Georgian legislation and through elected local selfgovernance bodies." The local self-governance actor is the municipality, which is described as a settlement (self- governing town) with administrative boundaries or a complex of settlements (self-governing commune) with administrative boundaries and an administrative centre, elected local self-governance bodies, local representative (Sakrebulo) and executive (Gamgeoba in a self-governing commune, mayor in a self-governing town) boards, which owns the resources and has its own budget. The municipality is the independent legal entity of public law.

The municipality has two types of authorities: the exclusive authority of the municipality and the authority that was delegated from the state government. The code on local self-government states that the management of natural resources of local significance, including water and forest resources, and the land resources which belong to the municipality, is the exclusive responsibility of the municipality. The municipality manages these resources according to Georgian legislation. The code on local self-government further states that the forest and water resources of local significance belong to the local municipality (No 1958IIs, 05/02/2014).

There are 59 self-governing communes and 12 selfgoverning towns in Georgia (No 1215, 09/07/2014). However, Akhmeta is the only self-governing entity that was given the rights to manage the protected area, including forests within its boundaries. The local selfgovernmental body of Akhmeta self-government, Sakrebulo, consists of 30 representatives, elected in democratic elections by the local population every four years. The Tushetians have six representatives in 


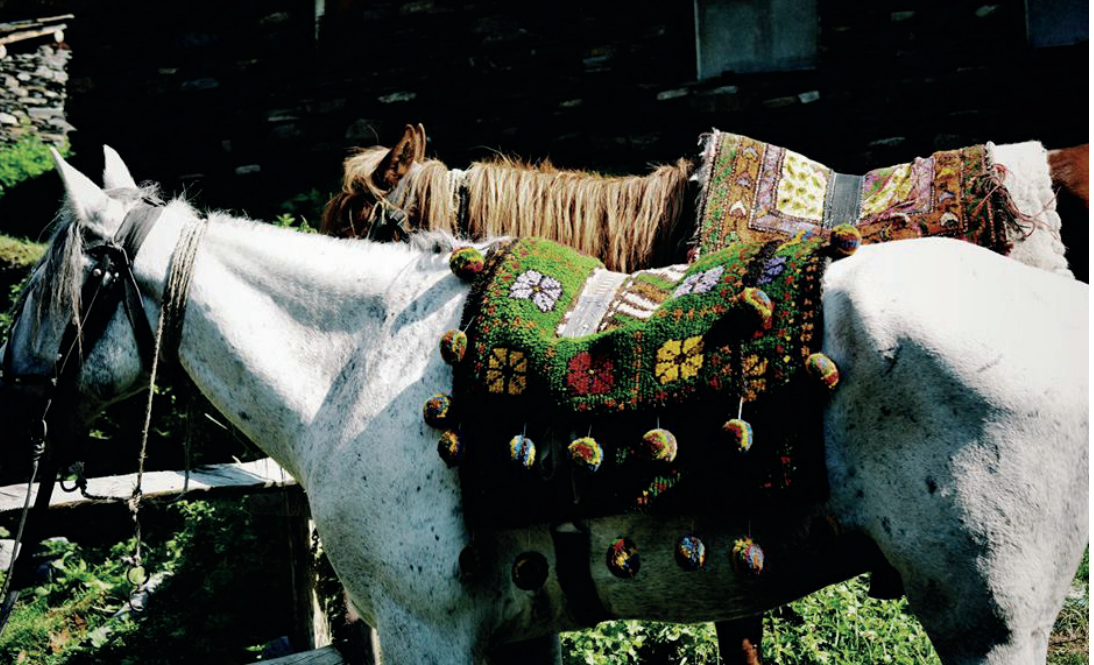

Figure 4 - Tushetian horses. (C) S. Idoidze

the Sakrebulo (Mr. D. Pavliashvili 2015 pers. comm.). Besides, the head of the executive body of Akhmeta self-government is also elected by the local population in democratic elections every four years (No 1958-IIs, 05/02/2014).

The Tusheti PL administration was created by Akhmeta self-government specifically for managing Tusheti PL. The administration has the status of a non-profit, non-commercial legal entity, with its own resources, rights and responsibilities, signs the contracts in its own name, and has other responsibilities that are essential for its effective operation. The main aims of the administration are:

- protecting the unique ecosystems, as well as the separate natural components of Tusheti PL from degradation and loss;

maintaining the national heritage, architectural monuments and historical and cultural landscape;

developing the necessary infrastructure to meet the growing recreational needs and demands on the resources of the high-mountain natural and historical-cultural landscape;

supporting the development of tourism;

conservation and restoration of wild flora and fauna in the ecosystems of Tusheti;

cooperating with international and non-governmental organizations;

carrying out tourism-recreational and educational activities;

supporting local traditional agriculture;

carrying out any other activities that are in accordance with Georgian relevant legislation. (Order-37, 24/05/2013).

\section{Management of Tusheti PL Forests}

Tusheti PL is managed by the local self-governmental body of Akhmeta municipality, while according to the Georgian system of protected areas, the management of all other protected areas is centralized. It is undertaken by the Agency of Protected Ar- eas (hereafter APA) under the Ministry of Environment and Natural Resources Protection of Georgia (hereafter MoENRP) (No-136-IIs, 07 March, 1996). The main reason why Tusheti PL is managed by local self-government is that the area is full of settlements and therefore the day-to day management of the socio-economic issues of the local population are essential and not part of the mandate of the body managing the protected areas. ${ }^{1}$

Tusheti PL is an exception also in terms of forest management. The National Forestry Agency (hereafter the NFA) of the MoENRP, which is managing the State Forest Fund ${ }^{2}$ of Georgia (No 2124-IIs, 22/06/1999), did not bear the responsibility or accountability, claiming that the area had protected area status.

Even during the designation of Tusheti PAs in 2003 by the law on Establishment and Management of Tusheti, Batsara-Babaneuli, Lagodekhi and Vashlovani Protected Areas, management of the Tusheti PL was already subordinated to Akhmeta municipality. However, until 2006 it was practically managed by the APA. This was mainly due to the lack of institutional arrangements in Akhmeta municipality that would have been necessary to manage a protected area. In 2006 the APA transferred the management of Tusheti PL to Akhmeta municipality, which at that time had only one person responsible for the whole area (Stanciu \& Ionita 2013; Mr. E. Lagazidze 2013 pers. comm.; Mr. A. Gogotidze and O. Ichirauli 2013 pers. comm.). The municipality created the management body, the Tusheti PL administration, in 2011. Its responsibilities include the protection and restoration of ecosystems of Tusheti PL, including forests.

However, defining the institutional structure of Tusheti PL has only partially solved the problem. A further dilemma was how to manage the forests? This was mainly associated with the status of Tusheti PL forests. The forest was officially under the State Forest Fund and was not transferred to Tusheti PL administration. Despite this, Tusheti PL administration was the only body legally responsible for managing the area and taking decisions on the forests (including issuing permits to the local population for collecting firewood).

The process of building the institutional arrangements for forest management in the area took some more years of negotiations with relevant state institutions. In September 2014 the amendments were introduced through two Governmental Resolutions (No 242, 20/08/2010 and No 46, 2014), which finalized the transfer of management of Tusheti PL forest to Akhmeta municipality. The amended laws officially named Akhmeta municipality as the only manager of the forests in Tusheti PL. Through this Tusheti PL administration officially became the only responsible

This reason was stated by the representatives of APA at several stakeholder meetings.

The State Forests Fund is divided into the Protected Areas and State Forestry Fund outside of PAs, including local forest funds (Forest Code No 2124-IIs, 22/06/1999). 
body for practical management of the Tusheti PL forests.

Till the end of 2014 Tusheti PL administration consisted of five staff member and four rangers working on seasonal basis (Mr. Z. Lagazidze 2014 pers. comm.). The administration lacked the necessary capacity to carry out proper forest management on the ground and proposed to increase the number of personnel to 13 from the year 2015. Proposed staffing was as follows: (1) director; (2) financial manager; (3) office manager; (4) tourism, recreation and marketing specialist; (5) natural resources management specialist; (6) agriculture development specialist; (7) infrastructure and urban development specialist; (8) ecological education and public relation specialist; (9) cultural heritage management specialist; and (10) four rangers.

This was the necessary staffing to secure Tusheti PL administration with the required number of professionals. Tusheti PL Administration proposed that the natural resources management specialist would be responsible for forest management as well. This kind of approach is practised in the APA (Matchavariani 2014). However, the municipality only agreed to add the position of the natural resources management specialist to the staffing of the administration (Mr. Z . Lagazidze 2015 pers. comm.).

To sum up, the Tushetians have their representation in the local self-government of Akhmeta municipality and they are participating in the democratic elections of the head of the local executive board. Moreover, given that the director, the key staff and all the rangers of the Tusheti PL administration are Tushetians, the local community is highly represented in the practical activities related to managing Tusheti PL forests.

\section{Use of forest resources in Tusheti PL}

Timber in Tusheti is used mainly for two purposes - firewood and construction material. Logging of timber is necessary to preserve the traditional lifestyle in Tusheti.

Timber as construction material is necessary for construction/reconstruction of traditional houses and out-buildings. Timber is used by locals (by $16 \%$ of households) for construction of balconies, stairs, roof basis, as well as doors and windows. Timber is used also for construction of livestock sheds (NCA CR \& KNPA 2013).

In Tusheti there is no gasification (and it is probably impossible to have it in the near future), so the main energy source is firewood. It is used for cooking and heating (by $62 \%$ of households). The alternative to firewood are solar panels, but they are quite expensive. Only local guesthouse owners have received them through grant programmes. Biogas is also not used as an energy source (NCA CR \& KNPA 2013). The annual average amount of firewood used by households is about $1500-2000 \mathrm{~m}^{3}$. The firewood is used by approximately $300-400$ households from the villages sit-

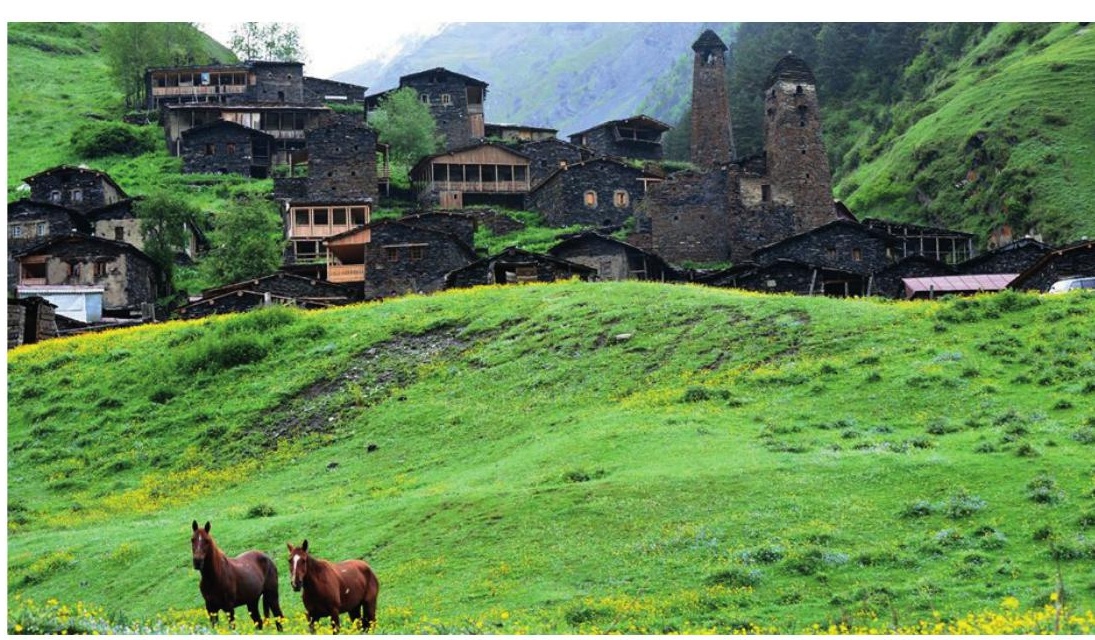

Figure 5 - Dartlo a village in Tusheti PL. (C) S. Idoidze

uated in the Piriqita, Gometsari, Chaghma and Chanchakhovani gorges (Mr. A. Gogotidze and O. Ichirauli 2013 pers. comm.).

Non-timber forest products used by locals are mushrooms, berries and herbs (for tea and medicine). They are used by approximately 38\% of the households, generally gathered in small quantities, mostly for self-consumption (NCA CR \& KNPA 2013).

The phenomenon of sacred forests exists in Tusheti. Sacred forests, together with the other sacred sites, are a very important component of religious life in Tusheti. Sacred forests are reserves of a kind, created

\section{Infobox}

Car route to Tusheti

The car route to Tusheti begins at the Kakhetian village of Fshaveli, reaches the Abano Pass (2926 m), the highest Georgian pass accessible by car, and ends in Omalo. The Abano Pass is only open for a few months per year. Even during this period, the road needs to be regularly cleared from stone falls and repaired. An offroad car is required for travel to Tusheti.

\section{Typical distances}

Tbilisi - Telavi: $160 \mathrm{~km}$

Telavi - Fshaveli village: $32 \mathrm{~km}$

Tbilisi - Akhmeta: $170 \mathrm{~km}$

Fshaveli village - Omalo: $72 \mathrm{~km}$

Tbilisi - Omalo: $188 \mathrm{~km}$, the journey takes 9 hours and a four-wheel drive car is required

Tbilisi - Qvemo Alvani: 190 km

Telavi - Qvemo Alvani: $22 \mathrm{~km}$

Akhmeta - Qvemo Alvani: $16 \mathrm{~km}$

Qvemo Alvani - Omalo: 90 km

\section{Cultural identity}

Tushetian sheep, Tushetian horse, a shepherd-dog, Tushetian cheese, Tushetian carpet, Tushetian thick felt, Tushetian hat, etc. form a single cultural and aesthetic space of Tusheti with a peculiar ethno-psychological order and a system of social rituals. 
and protected for religious considerations. These areas are almost intact and often distinguished by high aesthetic value and rich biodiversity (Resolution No16, 03/01/2014). The sacred forests occupy approximately 100 ha in Tusheti. There were some practical reasons behind the establishment of such forests: they are above the villages, where the drinking water for the villages originates, on steep slopes and peaks, where there is the risk of avalanches and landslides. No one is allowed to even take a branch of a tree from sacred forests. Such forests are a good example of how the forests would look without any kind of anthropogenic impact for a long time, or even never (N. Idoidze " $S a$ cred Forests"). Currently, most such forests are within Tusheti Strict Nature Reserve, IUCN Category I protected area (Mr. A. Gogotidze 2015 pers. comm.).

\section{The Tushetian population}

The people of Tusheti have occupied their territory on the north-facing slopes of the eastern part of the Caucasus Mountains for centuries. Due to its geographic isolation, historic information about Tusheti and its population before the Middle Ages is very scarce. However, Bronze Age artefacts discovered in Tusheti $\left(12^{\text {th }}-11^{\text {th }}\right.$ centuries B.C. $)$ confirm that people have inhabited Tusheti since ancient times.

Historically Tushetians used to live in the high mountains of Tusheti. In the $18^{\text {th }}$ century migration started from the Tusheti mountains into the plains. However, a significant number of people did stay in the mountains all year. In the mid- $20^{\text {th }}$ century the Soviet government forced the people to leave their mountain settlements. These processes transformed the lifestyle of the local population into a nomadic life (GCCW 2007).

The total Tushetian population is estimated to be about 10000 . Currently, most of the Tushetians spend the winter in the lowlands in three relatively large villages in Akhmeta municipality - Zemo Alvani, Kvemo Alvani and Laliskuri. They return to villages in the Tusheti mountains for the summer season. There are 48 villages in the Tusheti Mountains. The summer population in Tusheti is about $2000-2500$ people, and only about $20-40$ individuals stay there for the whole year (NCA CR \& KNPA 2013).

\section{Socio-economic activities}

Historically the Tushetian population is strongly linked to sheep-farming and the production of the well-known sheep cheese of the region. The most valuable goods produced in Tusheti are lamb meat and Guda cheese. Wool is used to make traditional products, such as carpets, hats, socks, bags or clothing, that are mainly sold to tourists. Another agricultural activity actively pursued during summer in the Tusheti mountains is cultivating potatoes.
According to the study of 2010, almost half (46.9\%) of the local population is engaged in some kind of economic activity during the summer months. The majority of these activities $(82.8 \%$ ) are connected with tourism, and $13.8 \%$ with sheep-farming. Generally, according to the local sheep farmers, $60-70 \%$ of local families are busy with sheep-farming. Each family has 300-400 sheep, some of them about 2000. In Tusheti there are approximately some 40000 sheep in total (NCA CR \& KNPA 2013, Resolution No-16, 03/01/2014).

From 2008 till 2014 the numbers of tourists visiting the area has increased from around 2000 to nearly 10000 (ISET 2014). The tourists bring money to the region, but the infrastructure has yet to keep up. There are only 48 guesthouses, hotels or B\&Bs in the area, with more under construction (ISET 2014). One major problem seems to be inadequate water supply for tourist facilities and a lack of sewage and waste management systems (Livny 2014).

\section{Other interesting aspects}

\section{Tushetian hospitality and cuisine}

"When a traveler on a horseback approaches a village, be should dismount and won't mount the horse until he passes the village" (Idoidze 2006). This is a rule that is observed even today by all locals and the same is expected of guests. In a traditional society, passing through a village on horseback was associated with the enemy and usually meant insult to the village. Later on this rule changed its initial meaning into a wordless expression of benevolence to the village, also as a greeting gesture. According to tribal traditions a guest of a house is a guest of the village as well. "A guest usually felt special attitude immediately after crossing the threshold of the house. In case a guest acted inappropriately and his behavior was considered by Tushetians to be opposing moral and traditional norms, a guest might soon feel outcast and neglected but nevertheless protected. Benevolence was still expressed to bim, but an invisible barrier would appear" (Idoidze 2006).

Tusheti boasts delicious local dishes. Khinkali is the best-known Tushetian dish. It is the name of boiled dumplings stuffed with mincemeat. Khinkali is usually prepared collectively, with the women showing their talent by skilfully folding many creases on Khinkali surface. As a desert Tushetian cheesecake (called Kotori) and cottage cheese fried in melted butter (called Khavitsi) are very popular local dishes. In addition to this, the shepherds' cuisine is quite original and is very much about making the most of the field conditions. These are mainly mutton stewed in its fat, called Kaurma, and Mtsvadi, which is a meat, put on wooden skewers and grilled over a Caucasus rhododendron fire. Last but not least - Tushetian sheep cheese, called Guda. The quality of the Guda cheese depends on the skill of the person who is making it, but its taste is mainly formed by the sheepskin guda, in which Guda cheese is kept (Idoidze 2006). 
Tushetian art

Local art in Tusheti has been formed by the shepherds' economy, which provided Tushetian homes with sufficient amounts of wool. Tushetian women were very well experienced in knitting and pressing felt and thick felt. They used to knit socks with beautiful ornaments, as well as Tushetian carpets, called Pardagi. The traditional outfit for the shepherd, called Nabadi, is closely associated with the local shepherds' economy and culture. Currently, traditional knitting and pressing thick felt still exists and its products are very popular among tourists and guests visiting Tusheti, for being made fully from natural and ecologically pure material (Idoidze 2006).

\section{References}

Ecoregion Conservation Plan for the Caucasus 2012. Caucasus Biodiversity Council. Available at: http://d2ouvy59p0dg6k.cloudfront.net/downloads/ ecp_2012.pdf (accessed: 30/04/2015)

GCCW (Georgian Center for the Conservation of Wildlife) 2007. Tusheti Protected Areas - Field Guide.

IUCN Caucasus Cooperation Center 2014. Forest Management in Tusheti Protected Landscape. Available at: http://enpi-fleg.ge/geoforestportal/publications / ForestManagementinTushetiProtectedLandscape_IUCNCCC.pdf (accessed: 30/04/2015)

ISET 2014. Tourism and rural development: The case of Tusheti. Available at: http://www.iset.ge/ blog/?p=3992 (accessed: 25/05/2015)

Livny, E. 2014. Kazbegi Rooms: with a view to improvement of regional development policies. Available at: http://www.iset.ge/blog/?p=3555 (accessed: 25/05/2015)

Nature Conservation Agency of the Czech Republic (NCA CR) \& Krkonose Mts National Park Administration (KNPA) 2013. Draft Management plan for Tusheti Protected Landscape.

Nugzar, I. 2006. Tusheti - A guide-book for travelers on customs and rituals. Agency of Protected Areas - Tusheti Protected Areas Administration.

Nugzar, I. n.d. Sacred Forests. Unpublished article.

Merab Machavariani, 2014. Opportunities and Challenges for Communal forestry in Georgia, on the case of Tusheti Protected Landscape. IUCN. Available at: http://enpi-fleg.ge/geoforestportal/ publications/OpportunitiesandchallengesforcommunalforestryinGeorgia_FinalReport_Machavariani.pdf (accessed: 30/04/2015)

Stanciu, E. \& A. Ionita 2014. Governance of Protected Areas in Eastern Europe - Overview on different governance types, case studies, and lessons learned. BfN-Skripten 360. Available at: https://www.bfn.de/
fileadmin/MDB/documents/service/Skript360.pdf (accessed: 30/04/2015)

WWF-Caucasus Programme Office (WWFCauPO) 2012. Forest management planning at WWFCaucasus Programme Office. Available at: http:// www.fleg1.enpi-fleg.org/index.php?id=49\&no_ cache=1\&tx_ttnews[tt_news] $=997 \& \mathrm{cHash}=$ a9 7803 709d0071d01 fa82ca2735b5dd (accessed: 30/04/2015)

\section{Resolutions and Laws}

Decree of Georgian Parliament on adoption of National Forest Concept (No-1742-Is, 26/12/2013).

Forest Code (No 2124-IIs, 22/06/1999)

Resolution of the government of Georgia on adoption of the National Biodiversity Startegy and Action Plan for 2014-2020 (No-343. 08/05/2014)

Georgian Law on "Protected Areas System" (No136-IIs, 07 March, 1996)

Georgian Law on "Establishement and Management of Tusheti, Batsara-Babaneuri, Lagodekhi and Vashlovani Protected Areas" (No-2086-Is, 22 April, 2003)

Resolution of Georgian Government on Approval of Management Plan of Tusheti Protected Areas (No16. $03 / 01 / 2014$ )

Akmeta Municipality Sakrebulo Order (No-33 25 March, 2011) on Establishment and Approval of Statute of Non-profit (Non-commercial) Legal Body "Tusheti Protected Landscape Administration"

The Resolution of Georgian Government on Approval of the Rules on Forest Use (No 242, 20 August 2010)

The Resolution of Georgian Government on Approval of the Rules on Transportation of Timber and the Technical Regulation of the Saw Mills in Georgia (No 46, amendment of 12 September 2014)

Georgian Code on local Self-government (No1958IIs, 05 February 2014)

The Resolution of Georgian Government on Approval of the Regional Development Programme of Georgia 2015-2017 (No1215, 09 July 2014)

\section{Author}

\section{Marika Kavtarishvili}

is a native from Tusheti and a graduate from Ivane Javakhishvili Tbilisi State University of Georgia, Faculty of International Law. She also holds an LL.M degree in European and International Law from the University of Bremen. Works at IUCN (International Union for the Conservation of Nature) as the ENPI FLEG Country Program Coordinator for Georgia and Acting Head of Office of IUCN Caucasus Cooperation Center. Contact: marika.kavtarishvili@iucn.org 